\title{
Many Ways to Walk a Mile in Another's Moccasins: \\ Type of Social Perspective Taking and its effect on Negotiation Outcomes
}

\begin{abstract}
:
The process of social perspective taking holds tremendous promise as a means to facilitate conflict resolution. Despite rapidly accumulating knowledge about social perspective taking in general, scholars know little about how the type of social perspective taking affects outcomes of interest. This study tests whether different ways to "walk a mile in another's shoes" cause different outcomes. By taking advantage of a computer-based simulation (where participants can learn about others by virtually walking around in the shoes of other characters), we assigned participants from Amazon's Mechanical Turk $(N=842)$ to five different perspective taking treatments or a control condition. Results show that perspective takers who receive information about the other party foster more positive relationships and make greater concessions than participants who did not receive information about the other party. Furthermore, those who experientially learned about the other party's perspective felt more positive about their relationships and made greater concessions during the negotiation than those who were simply provided information about the other party's perspective. No differences were found between virtually and imaginatively taking the perspective of others. These findings suggest the importance of accounting for the type of social perspective taking in studying how this social-cognitive process may facilitate conflict resolution.
\end{abstract}

Keywords: conflict resolution; interpersonal relationship; negotiation; social cognition; social perspective taking; virtual environment 


\section{Many Ways to Walk a Mile in Another's Moccasins: Type of Social Perspective Taking and its effect on Negotiation Outcomes}

Of the many levers that might be applied to resolving intergroup conflicts, social perspective taking (SPT) appears to be one of the most promising. If members of one party can more frequently and more accurately take the perspective of the other party, a wide array of outcomes are likely to improve (Batson, Early, \& Salvarani, 1997; Galinsky, Ku, \& Wang, 2005; Ickes, 2003). Thus, there has been increasing interest in techniques to cultivate and develop individuals' perspective taking capacity towards ends such as improving conflict resolution (e.g., Johnson \& Johnson, 2009b).

Virtual environments represent a particularly intriguing context for helping individuals develop their perspective taking capacities (Amichai-Hamburger, 2013). In these settings, individuals can inhabit the virtual character of someone who either shares their values, beliefs, and attitudes — or whose perspective differs in fundamental ways. By presenting increasingly challenging perspective taking tasks (i.e., asking participants to walk around in the shoes of increasingly different individuals), designers of virtual environments may help learners to progressively improve their social perspective taking capacities. By complementing social perspective taking training in these individual virtual experiences with training in intergroup conflict and real-world settings, a comprehensive approach to developing these capacities might ultimately be developed.

However, recent research has complicated our understanding of SPT. A small group of studies suggest that, under certain circumstances, SPT may lead to negative outcomes. For example, certain circumstances can actually make perspective takers increase their stereotyping of others. For example, if perceivers are highly affiliated with their own in-group (Tarrant, 
Calitri, \& Weston, 2012) or if the target is highly stereotype-consistent (Skorinko \& Sinclair, 2013) these ironic perspective taking effects may occur (Hodges \& Wegner, 1997). The implications of these recent studies are especially important. On the one hand, if SPT interventions help ameliorate conflict (or at least do no harm), trainings to improve people's SPT capacities might be disseminated widely. Given the quantity and severity of intergroup conflict across the globe, policy-makers might reasonably deploy SPT interventions somewhat aggressively. On the other hand, if SPT interventions have the potential to exacerbate tensions between groups, deploying these trainings must be done much more cautiously, and researchers must ascertain when and why particular effects occur.

Despite the importance of this issue, little scholarly attention has been paid to the type of SPT that participants enact. Because different types of SPT may involve different cognitive processes, it seems reasonable to anticipate that different outcomes may result from one type of SPT approach as compared to another. Thus, we speculate that investigating different types of SPT may illuminate when and why SPT appears to have disparate effects on outcomes. In this study, we aim to contribute to a developing understanding of how SPT affects outcomes (Gehlbach, 2004) through a specific focus on how perceivers learn about the perspective of their SPT target.

\subsection{Types of Social Perspective Taking}

SPT is the process of a "perceiver" discerning the thoughts, feelings, and motivations of a “target” (Davis, 1996; Gehlbach, Brinkworth, \& Wang, 2012). Recent research on SPT has begun to identify important moderating factors, such as the context in which the perspective taking occurs. For instance, whether the interactions between parties are in a cooperative versus competitive setting seems to affect outcomes (Pierce, Kilduff, Galinsky, \& Sivanathan, 2013). In 
addition, the characteristics of the perspective takers - such as the extent to which they identify with their in-group - also seem to affect outcomes (Tarrant et al., 2012). Yet, another potentially critical explanatory factor - the type of perspective taking that participants actually engage in has received little attention.

By type of SPT, we mean the extent to which and the manner in which a perceiver learns about the target's perspective. We view the types of SPT as arraying along two continua: the degree of knowledge about the target and the active/passive nature of the learning about the target. At one end of the first continuum a perceiver might know little or nothing about a particular target. For instance, contesting a bill with a customer service representative is typically a conflict-laden negotiation in which one has negligible information about the person on the other end of the phone call. By contrast, disagreements with a spouse typically entail perceivers and targets who know each other intimately. The second continuum ranges from SPT episodes where perceivers passively receive information about the target's perspective to episodes where perceivers learn about the target's perspective through active engagement typically in the form of role-taking exercises and simulations.

Perhaps the lack of strong theories about SPT partially explains this dearth of research on types of SPT. Extant theories describing the process through which SPT occurs - i.e., what motivates people to engage in the SPT process; what strategies they choose once they engage in SPT; how these processes differ across different contexts, perceivers, and targets; as well as how SPT then affects outcomes - are largely preliminary (e.g., Gehlbach \& Brinkworth, 2012; Gehlbach, Brinkworth, \& Wang, 2012; Zaki, 2014). Arguably, developmental psychology has the most advanced theorizing about SPT (Flavell, 2000; Selman, 1975), asserting that people's capacities to take the perspective of others changes substantially with age and evolves through 
qualitatively different stages. Especially because the present study investigates SPT within a virtual context - where novel types of SPT are possible - we faced a dearth of rich and relevant frameworks to draw upon.

In part, because scholars lack a robust theory describing how distinct types of SPT might affect different outcomes in unique ways, we focused on this potentially important area. Specifically, we designed our study to provide empirical evidence regarding the extent to which the type of SPT matters with respect to influencing outcomes. Our hope was that this evidence could then shape future theorizing as to different types of SPT function with respect to different outcomes.

\subsection{Types of SPT Included in the Present Study}

Because many studies ask participants to "walk around in the shoes of the other" in some form, we constrain our study to this genre of SPT strategies. Within this umbrella of approaches, we systematically varied the type of SPT along the two relevant dimensions. Specifically, in two conditions our participants acquired no substantial knowledge or information about the other party prior to the negotiation, whereas they did learn about the SPT target in the other four conditions. In those conditions where participants did receive information about the other party, they learned this information passively from the point of view of their own role in two conditions or actively by experiencing the other party's perspective (in the other two conditions). Finally, for those who learned about the other party by experiencing the other party's perspective, participants in one condition engaged in SPT virtually and in the other condition they took the perspective of their targets imaginatively.

Our rationale for these foci was three-fold. First, we noted that a number of the studies that found negative effects of SPT in conflict-related situations provided participants with no 
substantive information about the opposing party prior to their interaction. For instance, Epley, Caruso, and Bazerman (2006) found that instructions to take the other party's perspective led participants to behave egoistically and take more resources for themselves. Pierce et al. (2013) found that SPT instructions lead to unethical behavior in a similar set of studies. In both instances, the authors note the importance of competitive versus cooperative contexts. However, the experimental design of these studies was generally structured such that no information was provided about the perspective taking target ${ }^{1}$. In contrast, other SPT interventions where detailed information is provided about the target have resulted in positive outcomes such as altruistic behavior (Batson et al., 1997). Thus, we wished to see whether, within a competitive negotiation context, types of SPT that provided detailed contextual information about the other target (as compared to types of SPT that did not) might affect outcomes.

Second, the literature on cognitive biases is replete with examples of how framing and role conceptions affect people's information processing and subsequent behavior particularly with respect to outcomes that have implications for negotiations. For example, Van Boven, Dunning, and Loewenstein (2000) showed that people come to understand the value of the same object differently depending upon whether they are assigned to the role of a potential owner or buyer of the object. Of particular relevance to the present context, Yee and Bailenson (2006) found that walking around a virtual environment in the avatar of an elderly person caused a reduction of stereotyping of the elderly (as compared to inhabiting the avatar of a younger person). Thus, in our study we also wished to examine whether negotiation outcomes were affected by how information about the opposing party is learned - specifically, we contrasted the

\footnotetext{
${ }^{1}$ In Pierce et al.'s (2013) second study, the extent to which perceivers knew anything about the targets is unclear.
} 
passive learning about the other party with experientially learning the same information from that party's perspective.

Third, immersive virtual environment technology might allow individuals to engage in a heightened role taking experience in a way that is more experientially vivid than might be replicated through one's imagination. Specifically, Ahn, Le, and Bailenson's (2013) compared immersive virtual environment technology versus more traditional imaginative approaches in taking the perspective of color-blind individuals. They found that those who learned about color-blindness experientially were more inclined to help colorblind individuals than those who engaged in SPT imaginatively. Thus, we were also interested in testing conditions that specifically contrasted a virtual learning experience with an imaginative one.

\subsection{The Effects of Different Types of Social Perspective Taking}

Through a computer-based virtual reality simulation (Blascovich et al., 2002), we compared participants across a control condition and multiple approaches to walking around in the other party's shoes on key conflict resolution outcomes: relationship quality and resource allocation. We focused on these outcomes because prior scholarship identified improved relationships and savvier resource allocation as among the most consistently crucial in ameliorating conflicts. As Batson and Ahmad (2009) note, a great number of programs designed to improve relationships through prejudice reduction and increased cooperation between groups rely on SPT as a core lever (Aronson, 2000; Johnson \& Johnson, 2009a). In addition, a robust literature focused on negotiation identifies not only the need for disputants to cultivate a positive relationship over time, but to also identify optimal, win-win solutions where possible as they allocate scarce resources (Galinsky, Maddux, Gilin, \& White, 2008; Trötschel, Hüffmeier, Loschelder, Schwartz, \& Gollwitzer, 2011). Other important studies also suggest that SPT plays 
an important role in improving these outcomes between individuals and groups as well as at the intergroup level (Nordgren, Banas, \& MacDonald, 2011; Paluck, 2010).

\subsection{The Virtual Context of the Study}

Our virtual environment featured members from opposing groups representing those who prioritized business development (a golf-course owner) and those who prioritized conservation (a park ranger). The web-based virtual environment included a golf course abutting a pond with a surrounding nature preserve (see Figure 1a). All participants assumed the role of the golf-course owner and took a first-person perspective within the virtual world (rather than a third-person perspective where they could see their own avatar) because that has been shown to facilitate learning in virtual worlds (Lindgren, 2012). Thus, they viewed the virtual pond environment and characters as if they were looking through the eyes of the golf-course owner. In their role as the golf-course owner, participants ultimately negotiated with a park ranger about six issues (e.g., enlarging the pond, building a golf cart path, etc.). To immerse themselves in their role as the golf-course owner and to learn the owner's preferences, all participants walked through the virtual world while meeting a club member, pro-shop manager, and building contractor who shared information about the owner's perspective on the six issues (see Figure 1b). For example, the participants playing the role of the owner navigate to a club member character who explains in series of dialogue boxes why it is important for the pond and golf course to be managed by a single executive director. In one interaction, the club member tells the owner: "A lot of us feel that getting the executive in charge is probably the most important issue in the negotiation! As my friend on the board of directors said, it is absolutely vital for the health of the club." Participants also interacted with these non-player characters through open-ended text responses and interactive tasks that mirrored those of what an actual golf-course owner might have to do. 
For instance, in the interaction with the pro-shop manager character, participants must choose which golf club bag to display in the pro-shop window. When meeting with the building contractor, participants reviewed cost estimates and financial projections of putting in a new clubhouse.

In accord with our between-subjects experiment, after all participants were immersed into the role of the golf-course owner, their experiences differed by their random assignment to one of the following conditions:

\subsubsection{No Learning.}

(a) Control participants learned nothing about the park ranger's perspective and priorities.

(b) Instructions-Only participants also learned nothing about the ranger's perspective but were instructed to take the ranger's point of view by thinking, "about the ranger's perspective, even though it may be different than yours. Understanding how s/he perceives the situation can be helpful during the negotiation."

\subsubsection{Informational Learning.}

(c) Implicit Information participants received basic information about the park ranger's priorities, "Your board of directors thought it might be useful to get an understanding of the ranger's point of view. Thus, they are providing you with information about the ranger's priorities. Please read the following document to help prepare for the negotiation.” Thus, this group learned about the opposing perspective passively, from their perspective as the golf-course owner by reading a list of facts. For example, they learned the following information about the ranger's position regarding the size of the pond: 
The ranger is also very concerned about changing the size of the pond and wants to keep the pond the same size. The ranger thinks that any shift in size or depth of the pond would dramatically impact the pond's ecosystem, destroying a number of plants and setting off a chain reaction in the pond's food web.

Furthermore, there were no explicit instructions to take the ranger's perspective though participants may have inferred that they should attend to the ranger's point of view.

(d) The Instructions and Information condition combined conditions (b) and (c) by asking participants to take the ranger's perspective and by informing them about the ranger's priorities.

\subsubsection{Experiential Learning.}

(e) Rich Mental Simulation participants 'experienced' the ranger's perspective by reading a detailed script that directly mirrored the Virtual-Shoes condition (below). One excerpt reads:

You turn around and walk away from the reporter towards a tall green tree and high grass where Karen is standing. Karen is holding a pair of binoculars and wearing jeans and a white t-shirt. When you reach her she says "Hello Ranger! What a great day to be bird-watching! Wouldn't it be great if there were a better path around the pond to watch birds? I know you also favor a nature path around the pond in order to enrich visitors' experiences.

After experiencing the ranger's perspective in this way, they returned to their real role as the golf-course owner.

(f) Virtual-Shoes participants experienced the ranger's perspective by walking around the virtual world as the ranger, meeting and interacting with the ranger's constituents: a bird-watcher, environmental scientist, and veterinarian - three non-player characters who shared the ranger's perspective on the six issues. The structure of these interactions mirrored those that they had experienced while in the role of the golfcourse owner. Specifically, participants experienced the virtual world in first-person 
and interacted with non-player characters through clickable dialogue boxes, openended text responses, and interactive tasks. For example, the environmental scientist character shows participants (as they are temporarily experiencing the role of the ranger) a chart and tells them, "I should add that the one thing you really want to avoid is letting the pond get larger without making it deeper - as you can see from the chart, this is especially bad for the pond-ecosystem." Like the Rich Mental Simulation participants, after experiencing the ranger's perspective in this way, they returned to their real role as the golf-course owner.

After their common experience as the golf-course owner and condition-specific experience, all participants negotiated with the park ranger. To ensure that the ranger behaved uniformly towards all participants, we staged the negotiation through a complex decision tree (i.e., a computer generated set of responses; see Figure 2). ${ }^{2}$ Throughout the negotiation participants selected a choice from several options; the ranger responded by making counteroffers, allowing participants to choose from new options. This process continued until participants reached a decision on each issue. Within the simulation, golf-course owners were motivated to achieve their top preferences on each issue because they would earn larger commissions (see Figure 2). The golf-course owner's and ranger's preferences conflicted, and participants could only view their own commission table, not the ranger's.

With these conditions in mind, we anticipated seeing three distinct patterns in our data. First, we expected that receiving information about the ranger would engender more positive relationships and make participants more willing to make concessions during the negotiation. Specifically, participants in the No-Learning conditions only knew that the ranger was competing with them over scarce resources. Thus, we expected participants in these two groups

\footnotetext{
${ }^{2}$ Participants were not informed that the ranger was a pre-programmed set of responses.
} 
to fear the worst, thereby forming the least positive relationships and making the fewest concessions, i.e., taking the largest commissions. To investigate this hypothesized pattern we specifically compare the effect sizes on our two outcomes between the No Learning groups and the four other conditions ${ }^{3}$.

Second, we expected that for those groups that did receive information about the ranger, perceiving this information actively and experientially from the ranger's perspective would help participants process this information in a more favorable light. In other words, participants in the Experiential Learning conditions should form better relationships and make more concessions than participants in the Informational Learning conditions because they are processing the information about the ranger actively, through the ranger's eyes. In this case, we compare the effect sizes between the Informational- and Experiential Learning conditions for both outcomes.

Third, we expected that the richness of the virtual environment would allow participants to immerse themselves in the point of view of the ranger with a depth and richness that could not be paralleled by their imaginations. Thus, we expected to see that participants in the Virtual Shoes condition formed slightly more positive relationships and made more concessions than those in the Rich Mental Simulation condition. We compare the effect sizes between these two groups accordingly.

Because of the dearth of research on different types of SPT, we included two conditions for each type of learning - experiential, informational, and no learning - to potentially allow for increased generalizability of our results and to see whether the contrasts offered additional insights into findings from previous studies.

\footnotetext{
${ }^{3}$ In line with recent criticism of null-hypothesis significance testing (e.g., Cumming, 2014), we focus our results on $95 \%$ confidence intervals and effect sizes to the extent possible. Because these practices are not yet universally accepted, we also include traditional significance levels in Tables 2 and 3.
} 


\section{Methods}

\subsection{Participants}

We solicited participants from Amazon's Mechanical Turk "marketplace for work" - a website where people can post or work on tasks (Buhrmester, Kwang, \& Gosling, 2011). Our final sample $(N=842)$ was $56 \%$ male, $78 \%$ White, and 97\% native-English speakers. Their mean age was 30.6 years old $(9.23 \mathrm{sd})$ and median level of education was 3 years of college. Participants were paid $\$ 4.00$ for completing the study regardless of their negotiation performance. Despite explicit directions that participants could only participate once, four participants tried to participate for a second time and were removed from the data set.

\subsection{Measures}

Our primary dependent variables consisted of the negotiation relationship and the commission earned by each participant. We measured the negotiation relationship through a self-report scale (6 items, $\alpha=.89$ ) adapted from Gehlbach, Brinkworth, and Harris (2012). Participants rated their interactions with the ranger through items such as, "How much did you trust the ranger?" We computed the commission outcome by taking an unweighted composite of participants' commissions across the six issues.

In addition, we collected a number of ancillary measures to better understand the range of effects our various interventions had on participants. We grouped these measures into four categories: negotiation emotions (anxiety, enjoyment, and efficacy); perceived similarity to the ranger (values-based and behavioral); SPT measures (participants' SPT confidence, their own SPT effort, and their perception of the ranger's SPT effort); and motivation (competitive and cooperative). 
Within the category of negotiation emotions, we assessed the level of anxiety participants felt during the negotiation through a 5 -item scale $(\alpha=.85)$ consisting of items such as, "How tense did you feel during the discussion?" Enjoyment of the negotiation was assessed through a 4-item scale $(\alpha=.87)$ that included items such as, "Overall, how much fun was the process of negotiating with the ranger?" Negotiation efficacy assessed participants' confidence in their ability to negotiate effectively with the ranger. This scale (6-items, $\alpha=.87)$ included items such as, "How confident were you that you could stick up for yourself during the negotiation?" These three measures were adapted from previous studies (Gehlbach \& Barge, 2012; Gehlbach et al., 2008) for the current negotiation context.

Because perceived similarity plays such a central role in liking and relationships (Montoya, Horton, \& Kirchner, 2008), we included two measures of similarity which were adapted from a similarity scale used in previous research (Gehlbach, Brinkworth, \& Harris, 2012). Values-based similarity - the extent to which participants perceived that the ranger shared their values - was assessed through a 4 -item scale $(\alpha=.87)$. "In general, how similar is your point of view to the ranger's point of view?" is a representative item. Similarity in behaviors (4-items, $\alpha=.74$ ) included items such as, "How similar were the offers you made to the offers that that ranger made?"

Because the intervention consisted of different types of SPT, we wanted to measure the effect of the intervention on different aspects of SPT motivation. Specifically, we assessed participants' SPT confidence (6-items, $\alpha=.86$ ) through items such as, "How confident are you that you accurately guessed what the ranger was thinking?" We asked participants to report how much effort they put into taking the ranger's perspective through a 6-item scale $(\alpha=.85)$. A typical item was, "How much effort did you put into learning what the ranger's goals were?" We 
also wanted to learn whether the intervention affected participants' perceptions of how much effort the ranger put into taking their perspective. We assessed this construct through a parallel 6-item scale $(\alpha=.88)$ e.g., "How much effort did the ranger put into learning what your goals were?" The SPT-confidence scale was adapted from a previous study (Gehlbach, Brinkworth, \& Wang, 2012); the SPT-effort scales were developed specially for the present study.

To ascertain how different types of SPT might affect participants' motivational orientation to the negotiation, we examined participants' cooperative and competitive motivations during the negotiation. The cooperative scale (6-items, $\alpha=.77$ ) included items such as, "How motivated were you to compromise with the ranger?" Meanwhile, the competitive motivation scale (5-items, $\alpha=.87)$ included items such as, "How motivated were you to 'win' the negotiation?" Both scales were developed explicitly for this study.

\subsection{Procedures}

After accepting the task, completing the online consent form, and being randomly assigned to condition, all Mechanical Turk participants entered the virtual environment and were trained to navigate the virtual world.

We collected our data as four separate experiments, comparing: (1) the Virtual-Shoes and Control conditions, (2) the Virtual-Shoes and Implicit Information conditions, (3) the VirtualShoes and Rich Mental Simulation conditions, and (4) the Virtual-Shoes, Control, InstructionsOnly, Implicit Information, and Instructions and Information conditions. Our rule for terminating data collection was to upload funds into Mechanical Turk once per study; our goal was to try to obtain approximately 150 to 200 participants for the first three studies and 350 for the fourth. Initially, we planned to write this article as sequential studies. However, upon comparing the samples, we found them to be statistically indistinguishable on the demographic 
characteristics described in the Participants section. Thus, we collapsed the four experiments into a single data set to maximize statistical power.

The one complication arose from aggregating our data sets. Specifically, we had counterbalanced the order in which participants engaged in the Implicit Information, Rich Mental Simulation, and Virtual-Shoes conditions for the first three experiments. A small order effect for the Virtual-Shoes condition on the commission outcome emerged; however, this effect seemed easily explained by chance (i.e., it emerged only for the commission outcome, and only in the second experiment). Thus, we did not counterbalance the fourth experiment. Upon aggregating the data sets, significant differences within the Virtual-Shoes condition emerged for the commission outcome only ( $M_{\text {owner-then-ranger }}=236.86, s d=64.63$, CI 225.32, 248.39; $M_{\text {ranger-then- }}$ ${ }_{\text {owner }}=210.84, s d=65.80$, CI 201.50, 220.18; $t=3.45, p<.001$, Cohen's $\left.d=.40\right)$. Thus, we address this by presenting the results for commission broken out by counterbalancing order.

\section{Results}

Although our main analyses consist of tests for group differences between different SPT types, the descriptive statistics presented in Table 1 illuminate three findings that help to contextualize the main results. First, we find that the quality of the relationship that participants perceive is weakly correlated with the amount of commission that they earn $\left(r_{841}=-.14\right)$.

Second, we see that most of the ancillary measures that we collected have moderately strong correlations with perceived relationship quality - the exceptions being the weaker negative correlations of anxiety and competitive motivation. Third, the correlations between these same ancillary measures and the commission outcome are consistently weaker (with one exception).

Levene's test for equality of variance showed that the distributions of our focal outcome variables were not statistically different for each group $(t=2.04, p=.07$ for relationships and $t=$ 
$1.25, p=.28$ for commission). Thus, we used analysis of variance to compare the mean selfreported relationships and commission scores between the different conditions (see Figures 3 and 4). We conducted Scheffé post-hoc comparisons to provide conservative estimates of betweengroup differences. To compute effect sizes between the particular conditions of interest, we computed weighted averages of the means and standard deviations of the relevant groups and then computed Cohen's $d$.

The first pattern we sought to investigate involved the differences between those participants assigned to conditions where they learned nothing about the ranger and those assigned to the other four conditions. In comparing these groups, we found that the perceived relationships of those in the four learning conditions were more positive than those in the No Learning condition (Cohen's $d=.34$ ). When looking at the commission scores, participants in the four learning conditions conceded more than those in the No Learning condition (Cohen's $d$ $=.39$ ). Thus, the anticipated pattern held for both outcomes. See Figures 3 and 4 for the overall pattern and Tables 2 and 3 for more detail.

The second pattern we examined was to see whether - for those participants who received information about the ranger - processing the information about the ranger's perspective passively (i.e., receiving the information while in their role as the golf-course owner) or experientially (i.e., while temporarily taking on the role of the ranger) affected our two outcomes. Specifically, we compared the Informational Learning conditions against the Experiential Learning conditions. With respect to the perceived relationships that participants in these two groups experienced, those in the Experiential Learning condition had more positive relationships (Cohen's $d=.24$ ). These participants also conceded more during the negotiation (Cohen's $d=.50$ ). As before, the patterns we expected mirrored what we saw in our data. 
Finally, we compared participants who learned experientially about the ranger's perspective to see whether there were differences between learning about the other party's perspective virtually or imaginatively (i.e., the Virtual-Shoes and Rich Mental Simulation conditions). Those in the Rich Mental Simulation condition reported relationships with the park ranger almost as positive as those in the Virtual-Shoes condition (Cohen's $d=.07)$. These same participants conceded just as much in their negotiations with the park ranger (Cohen's $d=.02)$ as the participants in the Virtual-Shoes condition. Unlike the first two patterns in our findings, these results ran counter to our expectations.

In addition to these primary outcomes, we measured a host of other constructs that we anticipated might facilitate our understanding of how different types of SPT affect participants. Our hope was that these exploratory analyses might be used to generate hypotheses about the other effects different types of SPT had on outcomes related to conflict resolution. Because of the exploratory nature of this aspect of the study, the numerous comparisons between conditions, and the number of constructs examined, we present these results in Table 4 as descriptive. The table illustrates that there are no differences between condition for enjoyment, negotiation efficacy, or SPT effort. Participants in the No Learning conditions tend to be most anxious and most competitive. Meanwhile, the Experiential Learning participants report being the most similar to the ranger, the most confident in taking the ranger's perspective, the most likely to think that the ranger is trying hard to take their perspective, and the most motivated to cooperate.

\section{Discussion}

Our first pattern of findings, that learning about the SPT target tends to produce more positive relationships and greater concessions, suggests that the beneficial effects of perspective 
taking may require learning something about the perspective taking target (at least under certain circumstances). One could argue that, when individuals are instructed to take the perspective of someone else, but given little or no information about who this person is, there is no actual perspective to be taken. As a result, these perceivers may behave in ways that are indistinguishable from those not given SPT instructions. In this way, our focus on SPT type may help explain prior findings with divergent results from our own. For instance, Epley, Caruso, and Bazerman (2006) and Galinsky, Maddux, Gilin, and White (2008) found that perspective takers actually take more scarce resources in competitive negotiation scenarios.

By contrast, our perspective takers (in the Informational and Experiential Learning conditions) conceded more than those in other conditions. Though other possibilities exist, one plausible explanation for these conflicting findings is that when perceivers learn nothing about their SPT targets, they enter competitive negotiations fearing the worst. In the Informational and Experiential Learning conditions, our perceivers did not face this type of vacuous SPT target. Instead, they gained information about the values and priorities of the park ranger. As a consequence, perhaps they entered the negotiation with a more open and receptive attitude.

In our second set of findings, we found that experiencing the park ranger's perspective, as opposed to passively learning about it, resulted in more positive relationships and fewer concessions. This finding is congruent with the concept that the framing or bias with which individuals process information as they engage in the social perspective taking process can affect the outcomes of the SPT attempt (e.g., Maoz, Ward, Katz, \& Ross, 2002).

Finally, we found the Virtual-Shoes and Rich Mental Simulation groups to be indistinguishable. Given that people often fail to adequately re-create situational nuances in mental simulating their anticipated future experiences (Gilbert \& Wilson, 2007), the lack of 
difference between these groups surprised us. Perhaps when our imaginations are equipped with sufficiently detailed scripts, our minds can rival vivid virtual experiences (Harris, 2000). On the other hand, the "desktop" virtual system was relatively low in immersion. As virtual experiences become more perceptually realistic, the efficacy of these systems will improve (Cummings \& Bailenson, in press) and perhaps different results will emerge between virtual and imaginative perspective taking types.

In addition to these three main points, the ancillary outcomes provide a foundation for generating additional testable hypotheses about how these different types of SPT may be functioning. First, several theoretically plausible mediators appear to have been unaffected by the differences in these particular types of SPT. Participants within each of the conditions appear to have enjoyed the negotiation to the same degree, been comparably confident with regard to their negotiation efficacy, and put forth similar amounts of SPT effort. Thus, in trying to understand what was responsible for the effect of the intervention, these constructs seem to be unlikely mediating variables. On a related note, we find it intriguing that participants' perceptions of how much SPT effort the ranger exerted differed by condition. As suggested by others (Bruneau \& Saxe, 2012), a potentially fruitful direction for scholars interested in SPT and conflict resolution would be to test the effects of both trying harder to take the other party's perspective and conveying to the other party how much SPT effort they are putting forth.

Second, congruent with our previous speculation about perceivers who try to take the perspective of vacuous SPT targets, participants in the Instructions Only condition appeared to be more anxious during the negotiation and less confident in their ability to take the perspective of the park ranger than participants in most of the other conditions. Thus, studies that can 
identify whether the effects of information-less SPT on different conflict resolution outcomes are mediated by anxiety and/or lack of confidence would be especially useful.

Before concluding, it is worth noting some of the limitations of our study - some of which also generate additional important questions for future exploration. One of the main limitations is described above: We had to make a trade-off between aggregating our samples to enhance statistical power and the resultant issues with primacy/recency effects that we did not control for in every study.

Other limitations were more subtle. For example, we did not vary the content or tenor of how the ranger's constituents spoke about the ranger - this character was deliberately designed to produce neutral affect in perceivers. A surly or saintly SPT target might produce substantially different results. In addition, our focus was to examine the extent to which the type of SPT affected conflict resolution outcomes. We felt that a powerful way to make that point was through showing the differential effects of SPT type within the same "walking in another's moccasins" general approach to SPT. However, the broad genre of SPT or the specific types of SPT which are best for ameliorating conflicts may not be those tested in our study. For example, SPT interventions employed in situations where individuals can interact through open-ended dialogue (as opposed to being constrained to options and responses within a decision tree as participants were in our study) might prove to be more optimal for SPT interventions in conflict resolution contexts.

Thus, future studies that can shed light on the following questions will be particularly instructive: How important are primacy/recency effects in role-taking exercises? How important is the content of the SPT target's point of view (e.g., how would our results differ if participants 
in our Experiential Learning conditions had learned that the ranger held malevolent priorities)?

Which types of SPT are likely to leverage the greatest impact on outcomes of importance?

\section{Conclusion}

The world is rife with conflict at both the interpersonal and intergroup levels.

Developing the capacity to take the perspective of others is an especially promising approach to promoting more effective conflict resolution. However, recent research has made it clear that SPT can no longer be thought of as an unambiguously positive influence. Particularly in situations where perceivers are asked to take the perspective of vacuous targets, SPT interventions may backfire (Skorinko \& Sinclair, 2013; Tarrant et al., 2012). Thus, if SPT interventions are to be brought to bear on real-world problems, scholars must have increased clarity on when, where, and under what conditions they appear to help resolve conflicts.

The present research suggests that virtual environments might be particularly effective settings to train individuals in how to improve their SPT capacities. Although these types of trainings would likely need to be complemented and extended with intergroup conflict resolution practice in real-world settings, virtual environments present an important context for individuals to begin learning fundamental skills. However, in setting up these environments to teach SPT, researchers need to be mindful of our increasingly complex understanding of SPT. Recent research has shown the importance of accounting for the context in which SPT occurs and the characteristics of SPT targets (Pierce et al., 2013; Skorinko \& Sinclair, 2013; Tarrant et al., 2012). This study adds SPT type - specifically, the dimensions of how actively a perceiver learns about a target and how much information is learned - as an additional, important variable that may explain some of the disparate effects of SPT in prior studies. As scholars continue 
striving to enhance our theoretical understanding of SPT, we hope that SPT type receives increased attention. 


\section{References}

Ahn, S. J., Le, A. M. T., \& Bailenson, J. (2013). The effect of embodied experiences on selfother merging, attitude, and helping behavior. Media Psychology, 16(1), 7-38. doi: $10.1080 / 15213269.2012 .755877$

Amichai-Hamburger, Y. (2013). Reducing intergroup conflict in the digital age. In H. Giles (Ed.), The Handbook of Intergroup Communication (pp. 181-193). New York: Routledge.

Aronson, E. (2000). Jigsaw classroom. Retrieved June 30, 2002, from http://www.jigsaw.org/

Batson, C. D., \& Ahmad, N. Y. (2009). Using empathy to improve intergroup attitudes and relations. Social Issues and Policy Review, 3(1), 141-177.

Batson, C. D., Early, S., \& Salvarani, G. (1997). Perspective taking: Imagining how another feels versus imagining how you would feel. Personality and Social Psychology Bulletin, 23(7), 751-758.

Blascovich, J., Loomis, J., Beall, A. C., Swinth, K. R., Hoyt, C. L., \& Bailenson, J. N. (2002). Immersive virtual environment technology as a methodological tool for social psychology. Psychological Inquiry, 13(2), 103-124. doi: 10.1207/s15327965pli1302_01

Bruneau, E. G., \& Saxe, R. (2012). The power of being heard: The benefits of 'perspectivegiving' in the context of intergroup conflict. Journal of Experimental Social Psychology, 48(4), 855-866. doi: 10.1016/j.jesp.2012.02.017

Buhrmester, M., Kwang, T., \& Gosling, S. D. (2011). Amazon's Mechanical Turk: A new source of inexpensive, yet high-quality, data? Perspectives on Psychological Science, 6(1), 3-5. doi: 10.1177/1745691610393980 
Cummings, J., \& Bailenson, J. N. (in press). How immersive is enough? A meta-analysis of the effect of immersive technology on user presence. Media Psychology.

Davis, M. H. (1996). Empathy: A social psychological approach. Boulder: Westview Press.

Epley, N., Caruso, E. M., \& Bazerman, M. H. (2006). When perspective taking increases taking: Reactive egoism in social interaction. Journal of Personality and Social Psychology, 91(5), 872-889.

Flavell, J. H. (2000). Development of children's knowledge about the mental world. International Journal of Behavioral Development, 24(1), 15-23.

Galinsky, A. D., Ku, G., \& Wang, C. S. (2005). Perspective-taking and self other overlap: Fostering social bonds and facilitating social coordination. Group Processes \& Intergroup Relations, 8(2), 109-124.

Galinsky, A. D., Maddux, W. W., Gilin, D., \& White, J. B. (2008). Why it pays to get inside the head of your opponent: The differential effects of perspective taking and empathy in negotiations. Psychological Science, 19(4), 378-384.

Gehlbach, H. (2004). A new perspective on perspective taking: A multidimensional approach to conceptualizing an aptitude. Educational Psychology Review, 16(3), 207-234. doi: 10.1023/b:edpr.0000034021.12899.11

Gehlbach, H., \& Barge, S. (2012). Anchoring and adjusting in questionnaire responses. Basic and Applied Social Psychology, 34(5), 417-433. doi: 10.1080/01973533.2012.711691

Gehlbach, H., \& Brinkworth, M. E. (2012). The social perspective taking process: Strategies and sources of evidence in taking another's perspective. Teachers College Record, 114(1). 
Gehlbach, H., Brinkworth, M. E., \& Harris, A. D. (2012). Changes in teacher-student relationships. British Journal of Educational Psychology, 82, 690-704. doi: 10.1111/j.2044-8279.2011.02058.x

Gehlbach, H., Brinkworth, M. E., \& Wang, M.-T. (2012). The social perspective taking process: What motivates individuals to take another's perspective? Teachers College Record, 114(1).

Gehlbach, H., Brown, S. W., Ioannou, A., Boyer, M. A., Hudson, N., Niv-Solomon, A., .. . Janik, L. (2008). Increasing interest in social studies: Social perspective taking and selfefficacy in stimulating simulations. Contemporary Educational Psychology, 33(4), 894914. doi: 10.1016/j.cedpsych.2007.11.002

Gilbert, D. T., \& Wilson, T. D. (2007). Prospection: Experiencing the future. Science, 317(5843), 1351-1354. doi: 10.1126/science. 1144161

Harris, P. L. (2000). The work of the imagination. Malden: Blackwell Publishing.

Hodges, S. D., \& Wegner, D. M. (1997). Automatic and controlled empathy. In W. J. Ickes (Ed.), Empathic accuracy (pp. 311-340). New York: The Guilford Press.

Ickes, W. J. (2003). Everyday mind reading: Understanding what other people think and feel. Amherst, NY, US: Prometheus Books.

Johnson, D. W., \& Johnson, R. T. (2009a). An educational psychology success story: Social interdependence theory and cooperative learning. Educational Researcher, 38(5), 365379.

Johnson, D. W., \& Johnson, R. T. (2009b). Energizing learning: The instructional power of conflict. Educational Researcher, 38(1), 37-51. 
Lindgren, R. (2012). Generating a learning stance through perspective-taking in a virtual environment. Computers in Human Behavior. doi: 10.1016/j.chb.2012.01.021

Maoz, I., Ward, A., Katz, M., \& Ross, L. (2002). Reactive devaluation of an 'Israeli' vs. 'Palestinian' peace proposal. Journal of Conflict Resolution, 46(4), 515-546. doi: $10.1177 / 0022002702046004003$

Montoya, R. M., Horton, R. S., \& Kirchner, J. (2008). Is actual similarity necessary for attraction? A meta-analysis of actual and perceived similarity. Journal of Social and Personal Relationships, 25(6), 889-922. doi: 10.1177/0265407508096700

Nordgren, L. F., Banas, K., \& MacDonald, G. (2011). Empathy gaps for social pain: Why people underestimate the pain of social suffering. Journal of Personality and Social Psychology, 100(1), 120-128. doi: 10.1037/a0020938

Paluck, E. L. (2010). Is it better not to talk? Group polarization, extended contact, and perspective taking in eastern Democratic Republic of Congo. Personality and Social Psychology Bulletin, 36(9), 1170-1185. doi: 10.1177/0146167210379868

Pierce, J. R., Kilduff, G. J., Galinsky, A. D., \& Sivanathan, N. (2013). From glue to gasoline: How competition turns perspective takers unethical. Psychological Science, 24(10), 1986-1994.

Selman, R. L. (1975). Level of social perspective taking and the development of empathy in children: Speculations from a social-cognitive viewpoint. Journal of Moral Education, $5(1), 35-43$.

Skorinko, J. L., \& Sinclair, S. A. (2013). Perspective taking can increase stereotyping: The role of apparent stereotype confirmation. Journal of Experimental Social Psychology, 49(1), 10-18. doi: 10.1016/j.jesp.2012.07.009 
Tarrant, M., Calitri, R., \& Weston, D. (2012). Social identification structures the effects of perspective taking. Psychological Science, 23(9), 973-978. doi:

$10.1177 / 0956797612441221$

Trötschel, R., Hüffmeier, J., Loschelder, D. D., Schwartz, K., \& Gollwitzer, P. M. (2011). Perspective taking as a means to overcome motivational barriers in negotiations: When putting oneself into the opponent's shoes helps to walk toward agreements. Journal of Personality and Social Psychology, 101(4), 771-790. doi: 10.1037/a0023801

Van Boven, L., Dunning, D., \& Loewenstein, G. (2000). Egocentric empathy gaps between owners and buyers: Misperceptions of the endowment effect. Journal of Personality and Social Psychology, 79(1), 66-76.

Yee, N., \& Bailenson, J. N. (2006, August 24 -26). Walk a mile in digital shoes: The impact of embodied perspective-taking on the reduction of negative stereotyping in immersive virtual environments. Paper presented at the PRESENCE 2006 Conference: The 9th Annual International Workshop on Presence, Cleveland, $\mathrm{OH}$.

Zaki, J. (2014). Empathy: A motivated account. Psychological Bulletin, 140(6), 1608-1647. 
Table 1: Basic descriptive statistics for the central constructs under investigation: Means, standard deviations, and Pearson correlations.

\begin{tabular}{|c|c|c|c|c|c|c|c|c|c|c|c|c|c|}
\hline & $M$ & sd & 1 & 2 & 3 & 4 & 5 & 6 & 7 & 8 & 9 & 10 & 11 \\
\hline 1) Relationship & 3.65 & 0.75 & -- & & & & & & & & & & \\
\hline 2) Commission & 240.52 & 68.40 & -.14 & -- & & & & & & & & & \\
\hline 3) Anxiety & 2.30 & 0.89 & -.17 & .02 & -- & & & & & & & & \\
\hline $\begin{array}{l}\text { 4) Enjoyment } \\
\text { 5) Negotiation }\end{array}$ & 3.62 & 0.91 & .45 & .04 & -.13 & -- & & & & & & & \\
\hline $\begin{array}{l}\text { Efficacy } \\
\text { 6) Similarity - }\end{array}$ & 3.50 & 0.74 & .45 & .02 & -.34 & .45 & -- & & & & & & \\
\hline $\begin{array}{l}\text { Values } \\
\text { 7) Similarity - }\end{array}$ & 2.73 & 0.97 & .51 & -.35 & -.16 & .29 & .35 & -- & & & & & \\
\hline $\begin{array}{l}\text { Behaviors } \\
\text { 8) SPT }\end{array}$ & 3.14 & 0.75 & .53 & -.18 & -.11 & .36 & .29 & .54 & -- & & & & \\
\hline $\begin{array}{l}\text { Confidence } \\
\text { 9) Own SPT }\end{array}$ & 3.77 & 0.68 & .44 & -.11 & -.21 & .34 & .47 & .38 & .36 & -- & & & \\
\hline $\begin{array}{l}\text { Effort } \\
\text { 10) Ranger's SPT }\end{array}$ & 3.69 & 0.71 & .35 & -.11 & .02 & .34 & .23 & .32 & .34 & .56 & -- & & \\
\hline $\begin{array}{l}\text { Effort } \\
\text { 11) Cooperative }\end{array}$ & 3.26 & 0.74 & .61 & -.07 & -.11 & .36 & .44 & .49 & .42 & .41 & .46 & -- & \\
\hline $\begin{array}{l}\text { Motivation } \\
\text { 12) Competitive }\end{array}$ & 3.13 & 0.77 & .42 & -.35 & -.021 & .27 & .22 & .56 & .45 & .38 & .42 & .36 & -- \\
\hline Motivation & 3.50 & 1.00 & -.18 & .39 & .10 & .11 & .19 & -.31 & -.17 & -.06 & -.04 & -.06 & -.32 \\
\hline
\end{tabular}

Notes: $N=841$.

Approximate significance levels are as follows: for $|r s|$ ranging from 0 to $.05, p=n s$; for $|r s|$ ranging from .06 to $.08, p<.05$; for $|r s|$ ranging from .09 to $.10, p<.01$; for $|r s| .11$ and greater, $p<.001$. 
Table 2: Summary of group differences for Relationship outcome.

\begin{tabular}{lllllll}
\hline & \multicolumn{2}{c}{$\mathrm{N}$} & Mean & SE & sd & \multicolumn{2}{c}{$95 \%$ CI } \\
\cline { 2 - 7 } Control $^{\mathrm{a}}$ & 160 & 3.47 & .06 & .84 & 3.36 & 3.59 \\
Instructions-Only a $^{\mathrm{a}}$ & 65 & 3.42 & .09 & .70 & 3.24 & 3.60 \\
Information-Only $^{\mathrm{a}, \mathrm{b}}$ & 161 & 3.62 & .06 & .68 & 3.51 & 3.74 \\
Information \& Instructions $^{\mathrm{a}, \mathrm{b}}$ & 71 & 3.59 & .09 & .78 & 3.42 & 3.76 \\
Rich Mental Simulation a, b $^{\mathrm{R}}$ & 68 & 3.74 & .09 & .79 & 3.56 & 3.91 \\
Virtual Shoes $^{\mathrm{b}}$ & 316 & 3.79 & .04 & .70 & 3.71 & 3.87 \\
\hline
\end{tabular}

Notes: Conditions that share superscripts of the same letter indicate that no significant differences exist between those conditions (using Scheffé post-hoc comparisons) at the $p<.05$ level. $F=5.52, p<.001$. 
Table 3: Summary of group differences for commission outcomes.

\begin{tabular}{|c|c|c|c|c|c|c|}
\hline \multirow[b]{2}{*}{ Control $^{\mathrm{a}}$} & \multirow{2}{*}{$\begin{array}{r}\mathrm{N} \\
160\end{array}$} & \multirow{2}{*}{$\frac{\text { Mean }}{262.55}$} & \multirow{2}{*}{$\begin{array}{c}\text { SE } \\
5.20\end{array}$} & \multirow{2}{*}{$\begin{array}{c}\text { sd } \\
65.96\end{array}$} & \multicolumn{2}{|c|}{$95 \% \mathrm{CI}$} \\
\hline & & & & & 252.37 & 272.74 \\
\hline Instructions-Only a, c & 65 & 251.67 & 8.15 & 65.10 & 235.68 & 267.65 \\
\hline Information -Only a & 161 & 256.83 & 5.18 & 64.38 & 246.68 & 266.99 \\
\hline Information \& Instructions a, d & 71 & 247.54 & 7.80 & 61.94 & 232.24 & 262.83 \\
\hline Rich Mental Simulation ${ }^{b, c, d}$ & 68 & 222.92 & 7.97 & 74.23 & 207.29 & 238.54 \\
\hline Virtual Shoes (owner $\rightarrow$ ranger) ${ }^{a, b, d}$ & 123 & 236.86 & 5.93 & 64.63 & 225.24 & 248.47 \\
\hline Virtual Shoes (ranger $\rightarrow$ owner) ${ }^{b}$ & 193 & 210.84 & 4.73 & 65.80 & 201.56 & 220.11 \\
\hline
\end{tabular}

Notes: Conditions that share superscripts of the same letter indicate that no significant differences exist between those conditions (using Scheffé post-hoc comparisons) at the $p<.05$ level. $F=12.53, p<.001$. 
Table 4: Descriptive statistics of group differences for ancillary outcomes of the intervention: Mean, (Standard Errors), and [Confidence Intervals].

\begin{tabular}{|c|c|c|c|c|c|c|}
\hline & $\begin{array}{l}\text { Control } \\
(n=160)\end{array}$ & $\begin{array}{c}\text { Instructions } \\
\text { Only } \\
(n=65)\end{array}$ & $\begin{array}{c}\text { Implicit } \\
\text { Information } \\
(n=161)\end{array}$ & $\begin{array}{c}\text { Instructions \& } \\
\text { Information } \\
(n=71)\end{array}$ & $\begin{array}{l}\text { Rich Mental } \\
\text { Simulation } \\
\quad(n=68)\end{array}$ & $\begin{array}{c}\text { Virtual Shoes } \\
\quad(n=316)\end{array}$ \\
\hline Anxiety & $\begin{array}{l}2.46(0.07) \\
{[2.32,2.60]}\end{array}$ & $\begin{array}{l}\mathbf{2 . 6 8}(0.11) \\
{[2.47,2.89]}\end{array}$ & $\begin{array}{l}2.34(0.07) \\
{[2.21,2.48]}\end{array}$ & $\begin{array}{l}\mathbf{2 . 2 0}(0.10) \\
{[2.00,2.41]}\end{array}$ & $\begin{array}{l}2.13(0.11) \\
{[1.92,2.34]}\end{array}$ & $\begin{array}{l}\mathbf{2 . 1 8}(0.05) \\
{[2.09,2.28]}\end{array}$ \\
\hline Enjoyment & $\begin{array}{l}\mathbf{3 . 6 1}(0.07) \\
{[3.47,3.75]}\end{array}$ & $\begin{array}{l}\mathbf{3 . 4 3}(0.11) \\
{[3.21,3.65]}\end{array}$ & $\begin{array}{l}3.63(0.07) \\
{[3.49,3.77]}\end{array}$ & $\begin{array}{l}\mathbf{3 . 6 7}(0.11) \\
{[3.46,3.88]}\end{array}$ & $\begin{array}{l}\mathbf{3 . 6 9}(0.11) \\
{[3.47,3.91]}\end{array}$ & $\begin{array}{l}\mathbf{3 . 6 3}(0.05) \\
{[3.53,3.73]}\end{array}$ \\
\hline $\begin{array}{l}\text { Negotiation } \\
\text { Efficacy }\end{array}$ & $\begin{array}{l}\mathbf{3 . 4 3}(0.06) \\
{[3.31,3.54]}\end{array}$ & $\begin{array}{l}\mathbf{3 . 3 5}(0.09) \\
{[3.17,3.53]}\end{array}$ & $\begin{array}{l}3.49(0.06) \\
{[3.38,3.61]}\end{array}$ & $\begin{array}{l}3.62(0.09) \\
{[3.45,3.80]}\end{array}$ & $\begin{array}{l}\mathbf{3 . 5 3}(0.09) \\
{[3.35,3.70]}\end{array}$ & $\begin{array}{l}\mathbf{3 . 5 4}(0.04) \\
{[3.45,3.62]}\end{array}$ \\
\hline $\begin{array}{l}\text { Similarity - } \\
\text { Values }\end{array}$ & $\begin{array}{l}\mathbf{2 . 5 9}(0.08) \\
{[2.44,2.74]}\end{array}$ & $\begin{array}{l}\mathbf{2 . 4 6}(0.12) \\
{[2.22,2.69]}\end{array}$ & $\begin{array}{l}\mathbf{2 . 5 8}(0.08) \\
{[2.43,273]}\end{array}$ & $\begin{array}{l}\mathbf{2 . 7 7}(0.11) \\
{[2.54,2.99]}\end{array}$ & $\begin{array}{l}\mathbf{2 . 8 8}(0.12) \\
{[2.65,3.11]}\end{array}$ & $\begin{array}{l}\mathbf{2 . 8 8}(0.05) \\
{[2.78,2.99]}\end{array}$ \\
\hline $\begin{array}{l}\text { Similarity - } \\
\text { Behaviors }\end{array}$ & $\begin{array}{l}\mathbf{2 . 9 3}(0.06) \\
{[2.82,3.05]}\end{array}$ & $\begin{array}{l}\mathbf{3 . 0 2}(0.09) \\
{[2.84,3.20]}\end{array}$ & $\begin{array}{l}3.13(0.06) \\
{[3.02,3.25]}\end{array}$ & $\begin{array}{l}\mathbf{3 . 1 3}(0.09) \\
{[2.95,3.30]}\end{array}$ & $\begin{array}{l}\mathbf{3 . 2 8}(0.09) \\
{[3.10,3.45]}\end{array}$ & $\begin{array}{l}3.26(0.04) \\
{[3.17,3.34]}\end{array}$ \\
\hline $\begin{array}{l}\text { SPT } \\
\text { Confidence }\end{array}$ & $\begin{array}{l}\mathbf{3 . 6 5}(0.05) \\
{[3.55,3.76]}\end{array}$ & $\begin{array}{l}3.49(0.08) \\
{[3.33,3.66]}\end{array}$ & $\begin{array}{l}3.70(0.05) \\
{[3.60,3.80]}\end{array}$ & $\begin{array}{l}\mathbf{3 . 8 3}(0.08) \\
{[3.67,3.98]}\end{array}$ & $\begin{array}{l}\mathbf{3 . 9 0}(0.08) \\
{[3.74,4.06]}\end{array}$ & $\begin{array}{l}\mathbf{3 . 8 8}(0.04) \\
{[3.81,3.96]}\end{array}$ \\
\hline $\begin{array}{l}\text { Own SPT } \\
\text { Effort }\end{array}$ & $\begin{array}{l}\mathbf{3 . 6 1}(0.06) \\
{[3.50,3.72]}\end{array}$ & $\begin{array}{l}3.66(0.09) \\
{[3.49,3.83]}\end{array}$ & $\begin{array}{l}3.66(0.06) \\
{[3.55,3.77]}\end{array}$ & $\begin{array}{l}\mathbf{3 . 8 0}(0.08) \\
{[3.63,3.96]}\end{array}$ & $\begin{array}{l}\mathbf{3 . 7 8}(0.09) \\
{[3.61,3.95]}\end{array}$ & $\begin{array}{l}\mathbf{3 . 7 2}(0.04) \\
{[3.64,3.80]}\end{array}$ \\
\hline $\begin{array}{l}\text { Ranger's SPT } \\
\text { Effort }\end{array}$ & $\begin{array}{l}\mathbf{3 . 0 9}(0.06) \\
{[2.98,3.21]}\end{array}$ & $\begin{array}{l}\mathbf{3 . 1 0}(0.09) \\
{[2.92,3.28]}\end{array}$ & $\begin{array}{l}3.20(0.06) \\
{[3.09,3.32]}\end{array}$ & $\begin{array}{l}3.35(0.09) \\
{[3.18,3.52]}\end{array}$ & $\begin{array}{l}3.26(0.09) \\
{[3.09,3.44]}\end{array}$ & $\begin{array}{l}\mathbf{3 . 3 8}(0.04) \\
{[3.30,3.46]}\end{array}$ \\
\hline $\begin{array}{l}\text { Cooperative } \\
\text { Motivation }\end{array}$ & $\begin{array}{l}\mathbf{3 . 0 9}(0.06) \\
{[2.97,3.21]}\end{array}$ & $\begin{array}{l}\mathbf{3 . 0 4}(0.09) \\
{[2.86,3.23]}\end{array}$ & $\begin{array}{l}\mathbf{3 . 0 3}(0.06) \\
{[2.92,3.15]}\end{array}$ & $\begin{array}{l}2.99(0.09) \\
{[2.81,3.16]}\end{array}$ & $\begin{array}{l}\mathbf{3 . 3 0}(0.09) \\
{[3.12,3.48]}\end{array}$ & $\begin{array}{l}3.22(0.04) \\
{[3.14,3.31]}\end{array}$ \\
\hline $\begin{array}{l}\text { Competitive } \\
\text { Motivation }\end{array}$ & $\begin{array}{l}3.70(0.08) \\
{[3.55,3.86]}\end{array}$ & $\begin{array}{l}3.73(0.12) \\
{[3.49,3.97]}\end{array}$ & $\begin{array}{l}3.64(0.08) \\
{[3.49,3.80]}\end{array}$ & $\begin{array}{l}\mathbf{3 . 5 8}(0.12) \\
{[3.35,3.81]}\end{array}$ & $\begin{array}{l}3.41(0.12) \\
{[3.18,3.65]}\end{array}$ & $\begin{array}{l}3.29(0.06) \\
{[3.18,3.39]}\end{array}$ \\
\hline
\end{tabular}


Figure 1a and $1 b$ : Screenshots of the MUVE near the pond (1a) and speaking with a club member (1b).
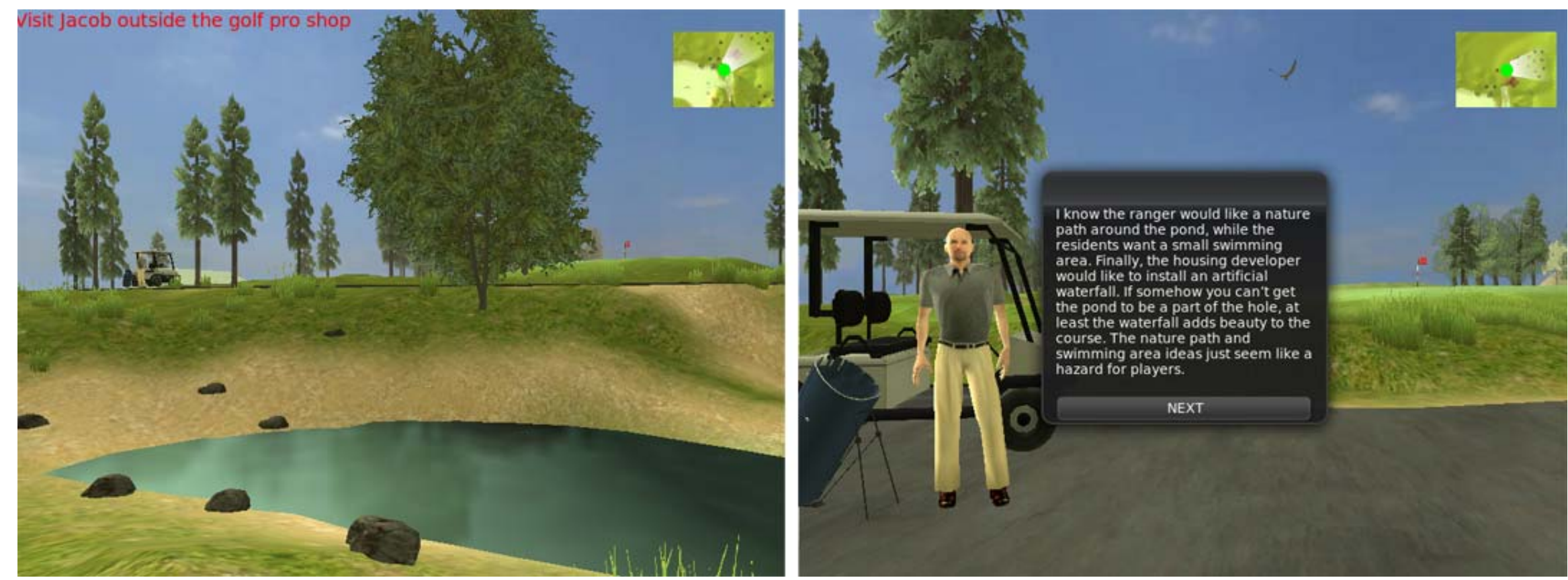
Figure 2: Screenshot of the golf-course owner's commission payouts (above) and negotiation (below).

\begin{tabular}{|c|c|c|c|}
\hline Issues (preferences $1=$ top choice) & Commission & Issues (preferences $1=$ top choice) & Commission \\
\hline $\begin{array}{l}\text { Purpose } \\
\text { Create a water hazard on the 13th hole (1) } \\
\text { Develop a waterfall on side of pond (2) } \\
\text { Designate as a small swimming area (3) } \\
\text { Nature Path (4) } \\
\text { No agreement reached (5) }\end{array}$ & $\begin{array}{l}\$ 500 \\
\$ 300 \\
\$ 100 \\
\$ 50 \\
\$ 0\end{array}$ & $\begin{array}{l}\text { Pond Access } \\
\text { Golf Cart Path (1) } \\
\text { Paved road (2) } \\
\text { Bridge over pond (3) } \\
\text { Multiple natural access points (4) } \\
\text { One access point (5) }\end{array}$ & $\begin{array}{l}\$ 500 \\
\$ 400 \\
\$ 350 \\
\$ 300 \\
\$ 50\end{array}$ \\
\hline $\begin{array}{l}\text { Management } \\
\text { Executive in charge (1) } \\
\text { Business-community task force (2) } \\
\text { Board with representatives from each group (3) } \\
\text { Neighborhood Council (4) } \\
\text { Scientific advisory board (5) }\end{array}$ & $\begin{array}{l}\$ 500 \\
\$ 250 \\
\$ 200 \\
\$ 100 \\
\$ 50\end{array}$ & $\begin{array}{l}\text { Abandoned House } \\
2^{\text {nd }} \text { clubhouse (1) } \\
\text { Coffee shop (2) } \\
\text { Remove house (3) } \\
\text { Bed and breakfast (4) } \\
\text { Wildlife rehab center (5) }\end{array}$ & $\begin{array}{l}\$ 250 \\
\$ 200 \\
\$ 150 \\
\$ 100 \\
\$ 50\end{array}$ \\
\hline $\begin{array}{l}\text { Size } \\
\text { Make slightly larger (1) } \\
\text { Make deeper and larger (2) } \\
\text { Make deeper (3) } \\
\text { Reduce pond size (4) } \\
\text { Retain current size and depth (5) }\end{array}$ & $\begin{array}{l}\$ 500 \\
\$ 450 \\
\$ 350 \\
\$ 200 \\
\$ 50\end{array}$ & $\begin{array}{l}\text { Surrounding Appearance } \\
\text { Rows of pine trees (1) } \\
\text { Actively managed native landscape (2) } \\
\text { Flowers and grass (3) } \\
\text { Flowering fruit trees (4) } \\
\text { Native vegetation (5) }\end{array}$ & $\begin{array}{l}\$ 550 \\
\$ 350 \\
\$ 150 \\
\$ 100 \\
\$ 50\end{array}$ \\
\hline \multicolumn{4}{|c|}{$\begin{array}{l}\text { The ranger replies... Look, the environmental damage done by people } \\
\text { walking off the paths around the pond is really trivial compared to what laying } \\
\text { down a whole paved path would do. However, I would be willing to give you } \\
\text { this golf cart path, if you are willing to agree to leave the size of the pond the } \\
\text { same. Otherwise, I think we should go with one access point and then if you } \\
\text { want to make the pond deeper, that is fine -- being able to minimize people's } \\
\text { access to the pond will offset any environmental damage done by dredging } \\
\text { the pond to make it deeper. }\end{array}$} \\
\hline \multicolumn{4}{|c|}{ How would you like to respond to the ranger now? } \\
\hline \multicolumn{4}{|c|}{$\begin{array}{l}\text { Great - let's go with the golf cart path then. And l'll allow you to retain the size of the pond as it is } \\
\text { currently. }\end{array}$} \\
\hline \multicolumn{4}{|c|}{$\begin{array}{l}\text { Fair enough. I'll give you want you want in terms of one access point. But then we agree to make the } \\
\text { pond deeper. }\end{array}$} \\
\hline \multicolumn{4}{|c|}{$\begin{array}{l}\text { I know I sound a bit like a broken record, but I really think this golf cart path is important for my golf } \\
\text { club members and for making my business profitable. }\end{array}$} \\
\hline
\end{tabular}


Figure 3: Mean differences in perceptions of the negotiation relationship (and 95\% confidence intervals) for each condition.

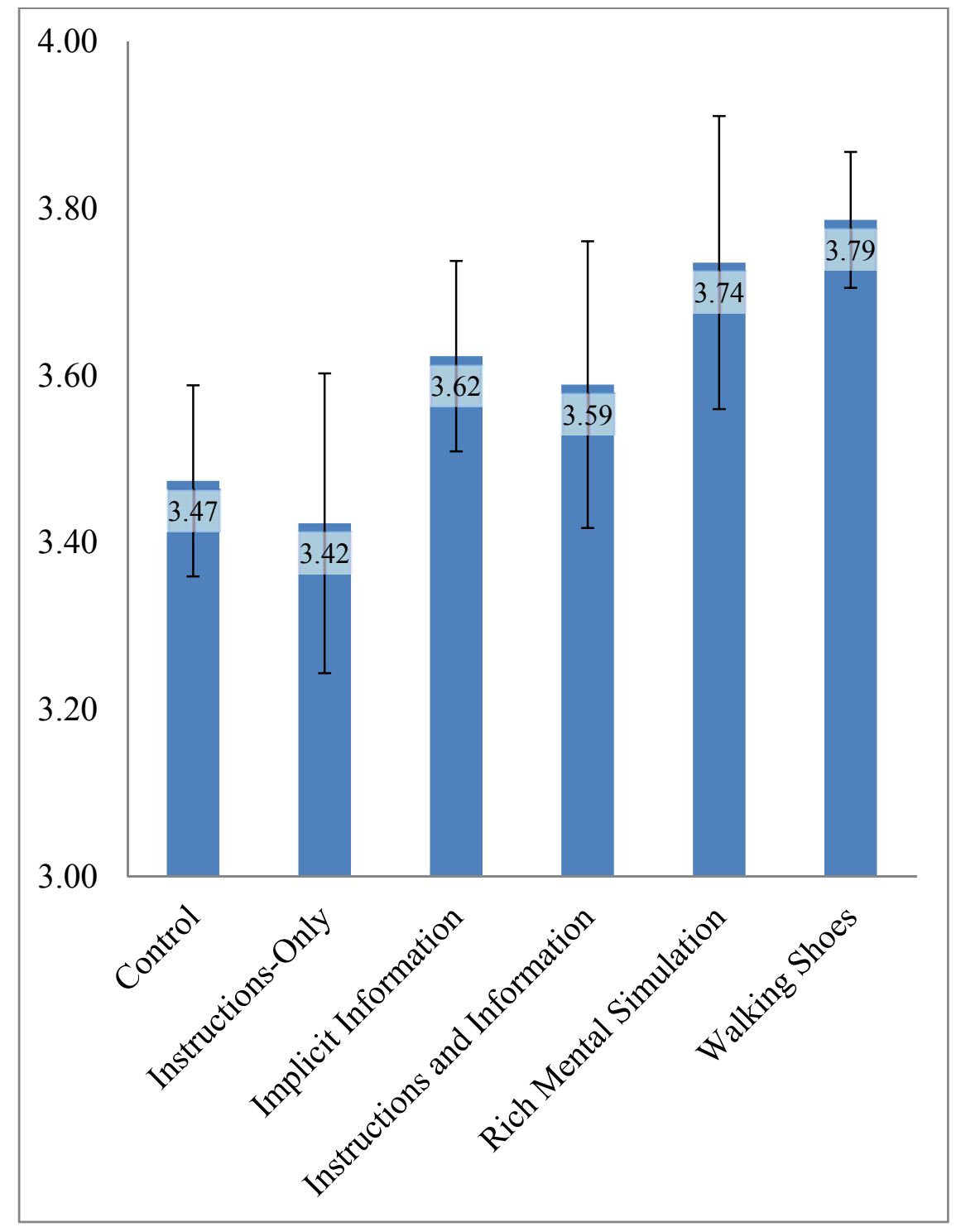


Running Head: MANY WAYS TO WALK A MILE

Figure 4: Mean differences (and 95\% confidence intervals) for each condition in commission.

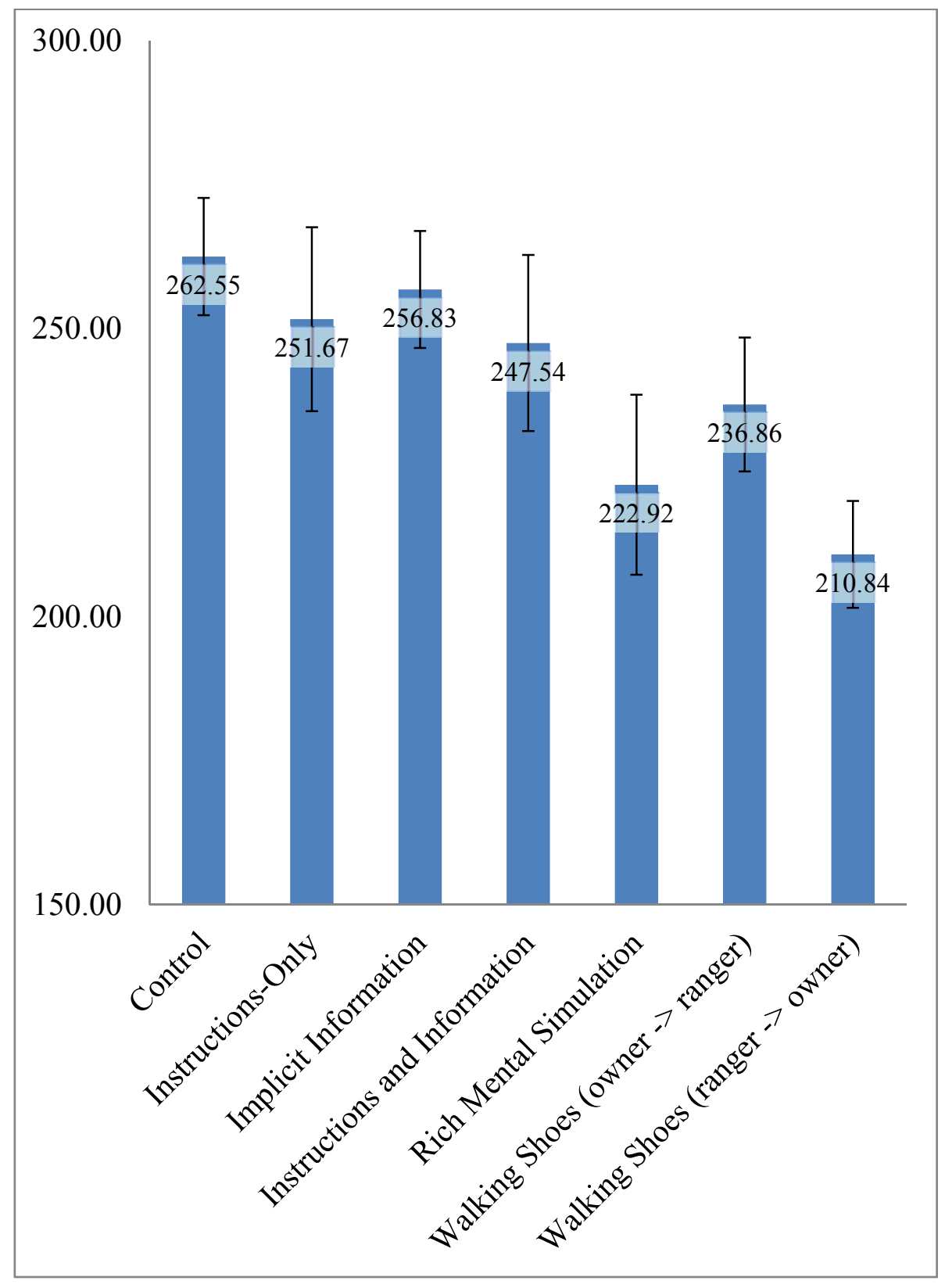

